\title{
Implementing Turnaround Strategy: Effect of Change Management and Management Competence factors
}

\author{
Francis O. O. Ayiecha ; Paul Katuse \\ Jomo Kenyatta University of Agriculture and Technology (Kenya) \\ United States International University (Kenya)
}

\begin{abstract}
This paper investigates the effect of change management and management competence factors on the implementation of turnaround strategy within organizations that would be either in declining or turnaround situations. Literature review on the, genesis of turnaround strategy implementations, the context inwhich the implementations were considered through a desktop research methodology and conclusions made from it.

A summary of the possible effects of the factors on turnaround strategy implementation is made upon which recommendations are made in order to enhance chances of successful turnaround strategy implementations. Suggestions for further research are made.
\end{abstract}

Key words: turnaround strategy implementation, change management, management competence.

\section{Introduction}

The concept of strategy has been in existence for several decades now and it is not likely to leave the research scene anytime in the future because it is intertwined with planning which must be present for organizational future success. According to Porter (1980) strategy concerned what an organization does in order to gain a sustainable competitive advantage.Hill and Jones (2001) defined strategy as an action that a company takes to attain one or more of its goals and therefore superior performance. Thompson and Strickland (1993)defined strategy as "the pattern of organizational moves and managerial approaches used to achieve organizational objectives and to pursue the organization's mission". Aosa (1998) defined it as "a means of solving strategic problems, which were a mismatch between the internal characteristics of an organization and the external environment in order to exploit opportunities existing in the external environment".

The extracts of the terminologies used for the definitions above, such as "what an organization is doing, moves and managerial approaches, direction or scope of organization, and actions employed", refer to the means for achievement, while the terms "meet or achieve long term objectives, competitive advantage, and superior performance", refer to the expected outcome.

For organizations to realize their strategic objectives, they must ensure that, their strategies are not only implemented but successful. Whonderr-Arthur (2009) defined implementing strategy or strategy implementation as "the translation of strategy into organizational action through organizational structure and design, resource planning and the management of strategic change".Thompson and Strickland (1999), pointed out that implementing strategy entails converting the organization's strategic Plan into action and then into results. Pearce and Robinson (2007) emphasized that, the three critical ingredients for the success of strategy are: the need for strategy's consistency with conditions in the competitive environment, need for strategy to take advantage of existing, emerging opportunities and minimization of the impact of major threats, and finally the need for strategy to place realistic requirements on the firm's resources. Machuki (2005) emphasized that one of the keys to successful strategy implementation was for management to communicate the case for organizational change so clearly throughout the ranks to carry out the strategy and meet performance targets. Management's handling of the strategy implementation process therefore, can be considered successful if and when the company achieves the targeted strategic and financial performance and shows good progress in realising its long range strategic vision (Machuki, 2005).

A lot of research efforts have continued to be put in this area of implementation of strategy because it touches on the very nerve of achievement of strategic organizational goals. For instance, research by Johnson (2004), indicated that 66 per cent of corporate strategy is never implemented, which is an indicator that many organizational failures occur due to lack of implementation of strategy and not because of lack of formulation of strategy. Crittenden and Crittenden (2008) found that the source of failures associated to lack of implementation of strategy originates from a likely possible gap between the formulation and implementation process of strategy.David (2003) cited in Machuki (2005) postulates that, management issues to strategy implementation include: annual objectives, devising policies, allocating resources, altering an existing organization structure, restructuring and reengineering, revising reward and incentive plans, minimizing resistance to change, matching managers with strategy, developing a strategy supportive culture, developing an effective human resource function and if necessary downsizing. 
In the business world today, both in developed and developing countries, economies have continued to experience a continuous decline in the performance of firms operating in various sectors due to various reasons. In general, the reasons emanate from both internal and external environmental conditions associated to those very firms. This is what leads the firm's management to formulate and thereafter implement turnaround strategies in order to revive the declining organization. In Kenyan economic survival is dependent upon many factors such as its political stability and the economic health of her business enterprises. The business enterprises on the other hand survive on the stability of their internal and external environment within which they operate. In the past a number of companies both in public and private sector experienced or continue to face challenges associated with economic and financial failures among other many reasons where some attempted revival tactics that did not work while a few survived (Sitati \& Bym Odipo, 2011). Revival tactics begin when management start realizing gradual business decline which is associated to failure. These eventually push the firms into Turnaround situations out of which strategic managers must create strategies for its revival.

While research on successful implementations of strategy, are important and relevant in various thematic areas, this paper examines the effect of both change management and management competence factors, on implementation of organizational turnaround strategy

\section{The Genesis and Context of Turnaround Strategy}

Organizational turnaround strategy implementations are usually an indication of a corporate crisis, which arise out of something threatening in its survival. Manimala and Panicker (2011)called such crisis "corporate sickness" while Pandit (2000) described them as organizational sickness that presents themselves gradually or suddenly with a threatening decline in performance after a series of internal actions or inactions or by external circumstances and other environmental factors.

Research on management of business turnaround span more than three decades and yet so much remains undone. For example, very low rates of successful recoveries from corporate sicknesses are still being, registered in research. It is estimated that approximately two-thirds of distressed companies are unable to recover (Hambric \& Schecter, 1983; Chowdhury \& Lang, 1996). The challenges associated with business failures have continued unabated therefore attracting continuous and further research. According to Ahn, Cho, and Kim (2000), most business failures are due to bad or poor management. Scherrer (2003) avers that 80 percent of business failures occur due to management's inefficiency to control the internal functions of business. Maheshwari (2000) attributes organizational decline to an outcome of inaction of managers characterised by past experiences, sunk investment, specialized assets bureaucratic control, internal political/cultural, managers commitment to status quo or outcome of inappropriate actions of managers in response to environmental reality characterized by legal, political, social and economic constraints.

\section{Turnaround Strategy and its Implementation Framework}

Wheelen and Hunger (2001) described Business Turnaround strategies as a form of retrenchment that emphasizes the improvement of operational efficiency. Turnaroundstrategy.net (2013) described a turnaround strategy as "an action plan that can give struggling business owners the guidance and direction they need to revitalize their company". Pandit (2000) suggested that any definition of turnaround should address the definition and measurement of performance; and the definition of turnaround cylce - that is a period of poor performance (decline phase) followed by a recovery in the performance (the recovery phase) and further emphasized that turnaround candidates are firms who's very existence is threatened unless radical action is taken and successful recovery cases demonistrate improved and sustainable environmental adaptation.

Pretorius (2009) summarised and proposed a definition of turnaround using the following words, "a venture has been turned around when it has recovered from a decline that threatened its existence to resume normal operations and achieve performance acceptable to its stakeholders (constituents) through reorientation of positioning, strategy, structure, control systems and power distribution".

According to Burbank (2005) a five step turnaround process accepted and supported by the Global Association of Turnaround Professionals is composed of: stuation analysis, changing the management, emergency actions, and returning to normalcy (profiability).

The purpose of turnaround strategy implementations in any company therefore, is to return the company back to a profitable and reducing debt situation and they are deemed to take a period of between five months even up to three years to complete, so that, if they were to be considered a success, then the company has to be financially strong and on its own for at least two years the turnaround plan is completed (Turnaroundstrategy.net, 2013).

John and Richard (1987) observed that business Turnaround strategy implementation, involved the reallocation of resources, in which management was, singled out as the most commonly reallocated resource. Lohrke, Bedeian and Palmer (2004) confirmed that, it was the top executives who's' responsibility was, to 
formulating and implementing effective business turnaround strategies needed to reverse declining organizational performance.

Francis and Desai (2005) explored the ability of suituational variables, manageable pre-decline resources and specific responses to decline in order to classify performance outcomes in declining firms and found that contextual factors such as urgency, and severity of decline, firm productivity and the availability of slack resources and firm retrenchment would determine the ability of firms to turnaround. They concluded that "overall, factors under control of managers contributed more to successful turnarounds than situational characteristics".

Maheshwari (2000) suggested that choices available for turnaround, which would ensure improved performance, were leadership change, domain change, retrenchment of both assets and people, technology up gradation, cost reduction and HR interventions. Bruton, Ahlstrom and Wan (2001) found that in the west, a firm in decline had to retrench or reduce its expenses before it would begin the turnaround process, which was the same for East Asian firms. They further found that in the west a greater success occurred when the firm's turnaround efforts focused on the single most important cause of the firm's decline (operating or strategic problems), while in East Asia it was, reported that problems facing most firms had little to do with operating problems related to cost in the firm's core business. Further, in the west there was an assumption that the CEO of a firm had to be, replaced in a turnaround effort while in East Asia due to high levels of stock ownership by owner/manager in most cases at over 50\% CEO replacement in turnaround would not be mandatory. It was also, generally believed in both the west and East Asia that the faster the turnaround efforts began the more likely it would be successful.

Slatter, Lovett, and Barlow (2006) developed an approach for achieving a successful business turnaround or recovery plan whose seven essential ingredients were:

$\begin{aligned} \text { i. } & \text { Crisis stabilisation } \\ \text { ii. } & \text { New leadership } \\ \text { iii. } & \text { Stakeholder management } \\ \text { iv. } & \text { Strategic focus } \\ \text { v. } & \text { Critical process improvements } \\ \text { vi. } & \text { Organisational change } \\ \text { vii. } & \text { Financial restructuring }\end{aligned}$

Further suggestions by Slatter et al. (2006) were that, to succeed in realising critical process improvements during business turnaround of a company, required focus on cost, quality, and time. The generic business turnaround strategies found to address the three focus areas were improved sales, improved marketing, cost reduction, quality improvements, improved responsiveness, improved information, and control systems. They further emphasized that when considering production or operating strategies necessary for the effectiveness of business turnaround, some of the measures include raw material costs reduction, investment in $\mathrm{R} \& \mathrm{D}$ and innovative technologies so as, to achieve competitive advantage. Hofer (1980) suggested that market penetration and niche positioning were, identified as valuable strategies for the successful corporate business turnarounds while according to Rosario, Kawamura and Peiris (2004) maintained that successful businesses competed on quality rather than on costs, with a view to developing competitive advantage. The measures for marketing strategies necessary to promote successful business turnaround include: promotional activities, aggressive pricing, entering newer markets and focusing on core business (Rosario, Kawamura, \& Peiris, 2004).

Scherrer (2003) emphasized the need for a management turnaround to begin with the identification of a state of decline to be followed by an immediate turnaround although he attributed a successful turnaround to the presence of a strong management team and sound business core. He further clarifies that the key elements to any successful business turnaround were from the highest priority: sound core business followed by; leadership of competent management followed by; capital for use throghout the process; and finally followe by the trust and support of the company's stakeholders. He however, concluded that the frame of the turnaround will vary depending on the above elements and on the severity of the decline.

Panicker and Manimala (2011) suggested that bringing organizations back to health required entrepreneurial strategies at two levels namely from the negative to breakeven and from breakeven to the positive terming it "a doubly entrepreneurial act". Their study confirmed that "successful turnarounds were accomplished through progressive building up of organizational competencies in line with the stage theory(through strategies such as employee engagement, cost rationalization, lean management, image building, and focusing on core business) before taking up aggressive growth and expansion strategies".

Maheshwari and Ahlstrom, Turning around a state owned enterprise: The case of scooters in India Limited (2003) found that: "the business environment; the firm's decision making process; its leadership characteristics; and the stakeholders' responses all influenced the firm's action choices and turnaround process". Haron, Rahman and Smith (2013) found that success of corporate turnaround was as a result of an effective 
leadership style capable of motivating and supporting the employees while making strategic changes on capital, financial well-being and operations of the organization.

Manimala and Panicker (2011) found that corporate sickness was one of the major socio-economic problems of developing as well as developed nations which gradually drives organizations into turnaround situations. Pandit (2000) observed two conclusions that could be made on corporate turnaround as being: that the incidence of turnaround situations were significant and that out of the firms suffering significant or sustained declining performance, a greater number proceeded to fail rather than recover further asserting that, a better understanding of turnaround could lead to a greater number of declining firms to successfully recover.With these issues in mind, it is hopped that identifying the effect of both change management and management competence factors on implementation of turnaround strategy implementation, would expand the scope of remedies for raising the success rates of organizational turnaround implementations.

\section{Literature Review}

The Stage theory of successful turnaround by Manimala (1991) identified four important stages in any successful turnarounds namely: arresting sickness, focusing on core business, expansion and growth, and institutionalization through culture building. It lays emphasis on turnaround managers to adopt a stage wise procedure when implementing their strategies. On the other hand, the Causal model of organizational performance and change of Burke and Litwin (1992) used to analyse, understand, and predict organizational change provides some guidance when trying to understand how organizations work within situations of chaos which would be likened to that of an organization that is in a Turnaround situation would both guide in the identifying or implying the relationship between both factors and turnaround implementation strategy.

\section{The effect of change management on turnaround strategy implementation}

Efforts made by researchers to define change management indicate no consensus on a common definition. According to Moran and Brightman (2001) change management is the process of continually renewing an organization's direction, structure, and capabilities to serve the ever-changing needs of external and internal customers. Tim (2006) described change management as that which incorporates the organizational tools that can be, utilized to help individuals make successful personal transitions resulting in the adoption and realization of change.

In this study, the researcher adopts Moran and Brightman (2001) definition of change management for its broad approach in which change management is recognized as a process for continuous monitoring not only the direction but the structure and capabilities of the organization in order to meet both internal and external customer's needs in line with its mission and strategic plans.

The causal model of organizational performance and change indicate that there are direct causal effects between external environment and that of individual or organizational performance. It further indicates that there is a direct causal effect between organizational culture and other variables such as leadership, systems (policies and procedures), and individual needs/values. However, any causal effect between organizational culture and organizational or individual performance is through motivation.

A study by Simon (2012) confirmed that some of the important factors that influence the outcome of process improvement programmes in organizations include strategic alignment, structural alignment, IT alignment, executive commitment, and employee empowerment. Other factors he found to be significant and critical to the success of process improvement programmes were: value and clarity of the proposed changes, pace of the change, inherent culture of an organization, sustainability of the change, and skills.

Thompson and Strickland (1999) emphasized the need for management to communicate the case for organizational change so clearly and persuasively that there is determined commitment throughout the ranks to carry out the strategy and meet performance targets in order to achieve a successful implementation of strategy. Some researchers held the view that top management change in organizations was widely recognised as a precondition for successful business turnarounds (Hofer, 1980; Bibeault, 1982;Slater, 1999).

According to Gieves (2000), the right way of managing people for adapting to and adopting change is achievable by changing their cultural norms and eventually make the change successful in the long-run.

Smith (2003) mentioned that to manage radical change effectively, some of the things one needs to consider are, communication to show support of the process change project and effective leadership to coordinate deployment of resources in order to achieve performance breakthroughs required to accomplish the strategic objectives which are the possible outcomes of application of innovative ways of doing business.

Gilley, Gilley and McMillan (2009) enumerated three types of change namely: transitional or gradual change; transformational or radical change, and developmental or continuous dynamic change in which they emphasized that whatever the type of change in an organization, it affects people, organizational structure, procedures or technologies of the organization. 
Managers' measure change effectiveness for only transformational or developmental change and the parameters for determining the effect of change on business operations include: measuring increased processing speed, increased customer satisfaction, reduction in backlog and, improved accuracy (Gilley, Gilley, \& McMillan, 2009).

By (2005) pointed out that a number of researchers reported a failure rate of around 70 per cent of all change programs initiated but wondered that there was consensus to the effect that the pace of change had never been greater than the ever evolving business environment leading to a concurrence that successful management of change highly required skill. Tyrol (2007) recommended that, for an organization to implement change management there has to be definition and implementation procedures, technologies to deal with changes in the business environment and profit because of changing opportunities. Change is necessary to maintain a competitive edge, although it is not always a smooth process (George \& Jones, 2008).

Waldersee \& Griffiths (2004) looked at organizational change in terms of participative approach whose assuption was that employee support is a pre-requisite of change and the unilateral approach whose assumption was that behavior must be changed first and attitude will follow found that, unilateral implementation approaches were more effective than participative.

Lorenzi and Riley (2003) looked at "people side issues" during implementations of new information systems recommended that anyone wishing to make changes within an organization, with minimum levels of trauma, must first understand the organization's power bases structures, reward systems, and other people issues. This was because understanding them, it was critical for developing appropriate strategies at the appropriate times and for involving the key players within the organization.

Research by Kavanagh and Ashkanasy (2006) on change management examined mergers between three large multi-site public-sector organizations. They specifically investigated leadership and change management processes, and concluded that leaders needed to know how they would carefully select the method or approach for managing change, how to develop a new culture, how to establish effective channels of communication at all levels of the organization, to incorporate stakeholders, and how to lead in a positive manner.

Sutevski (2012) compiled 28 factors some of which were, identified by other researchers, which caused resistance to organizational change. These were threat of power on an individual or organizational level; losing or alternative increase of control on the employees; economic factors; image, prestige and endangerment of reputation; threat of comfort, job security or interpersonal relations; reallocation of the resources; acquired interest to new groups; and implication on personal plans.

Other factors included too much dependence on others, misunderstanding the process, mistrust to initiators of change, different evaluation and perception, fear of the unknown, necessity to change habits, previous negative experiences, weakness of the proposed changes, and limited resources. Others were bureaucratic inertia, selective information processing by employees, uninformed employees, and peer pressure, skepticism about the need of change, increasing workload, and short time to performing change. For effective change, management must address all issues of resistance to change.

Aladwani (2001) explored employee resistance to ERP implementation. The objective of the study was, to establish change management strategies for ERP implementation. The study recommended that in order to overcome users' resistance to change, top management had to: study the structure and needs of the users and the causes of potential resistance among them; deal with the situation by using the appropriate strategies and techniques in order to introduce ERP successfully; and evaluate the status of change management efforts. Motivation is one of the methods of reducing resistance to change. Tower (1994) recommended that effective motivation package for an organization needed to be, widely spread in order to give equal chances and opportunities for all employees pointing out that some of the employee motivational methods were inducement through salary increases, bonuses, job enlargement, job enrichment, job rotation, promotion, offering higher responsibility, and acknowledgement of higher performance achievement of employee.

Szamosi and Duxbury (2002) focused their study on development of measures for organizational support and non-support of revolutionary change. They found both measures to be strongly linked to both organizational outcomes (organizational commitment, Job satisfaction, and managerial support) and employee/individual outcomes (Stress, burnout, and perceived organizational support). They demonstrated that when behaviors supportive of revolutionary change were undertaken, there would be a positive impact on critical outcome variables. However, behaviors to the contrary, negative impact on both the organization and the employee.

\section{The management competence's effect on Turnaround strategy implementation}

ACAS (2009) highlighted a management competency framework with positive and negative behavioral indicators and identified the first five top competencies which affect work related stress as: managing workload 
and resources, participative approach, individual consideration, communication, and empathy whose indicators are listed in appendix I.

Managers' competencies are the set of skills that managers must have to be effective. The IMF management competencies framework serves as a booster for senior managers' management skills also serves as a basis on which to assess managers within and across departments.

Harold (1984) described management as the art of getting things done through and with people in formally organized groups". Hill and Jones (2001) saw management as both an art because of making people more effective than they were before and a science because of how it is, done. Due to the role, they play in an organization, management need to have the competencies to execute the five management functions of management namely planning, organizing, commanding, co-coordinating and controlling.

King, Fowler and Zeithaml (2001) stated that, "competencies combine knowledge and skills which represent the underlying knowledge base and the set of skills required to perform useful actions". They pointed out that the four characteristics of competencies included: tacitness, robustness, embeddedness, and consensus and found that middle managers whose competencies were labeled more tacit, more robust and more embedded tended to outperform those who did not. They also found that after restructuring of an organization, accompany can survive everything but the defection of its middle managers.

Dulewicz and Herbert (1999) explored the key personal characteristics associated with long term managerial success as measured by increases in responsibility over a seven to eight year period using remuneration, numbers of staff, budget responsibility and organizational seniority as indicators and found that managers who had, higher risk taking, better planning, greater persuasiveness and better at motivating other people competencies, progressed at a higher rate than those who were less well-endowed with these competencies.

Snow and Hrebiniak (1980) examined relationships among strategy, distinctive competence, and organizational performance, focusing on the perceptions of top managers in four industries. The found that the managers perceived four strategy types, Defender, Prospector, Analyzer, and Reactor, to be present within their industry. Defenders, Prospectors, and Analyzers all showed competence in general and financial management. Beyond these two functions, Defenders and Prospectors had identifiable but different configurations of distinctive competence, while Analyzers' special capabilities were considerably less apparent. Reactors, as expected, had no consistent pattern of distinctive competence. Although the data were only suggestive, Defenders, Prospectors, and Analyzers consistently outperformed Reactors in competitive industries, but not in an industry that is highly regulated.

There cannot be effective management without managers who are endowed with the required competencies to implement relevant strategies. John and Richard (1987) observed that business turnaround strategy involved the reallocation of resources, and that the most commonly reallocated resource in the implementation of a Business Turnaround strategy was management. How then do the skills or competencies of management affect turnaround?

Castrogiovanni, Baliga and Kidwell Jr. (1992) tried offering suggestions to the executive level managers on how to deal with continuously declining business particularly on how to determine whether the current CEO or a replacement should lead a turnaround effort. They recommended that any CEO change should be first cost justified, and then determination whether business has a difficulty in adapting to the niche, market, or level of its surrounding environment, and finally a new CEO with appropriate credentials/competencies (matching skills with problem severity) be selected. Gerald (2004) suggested that, management systems would be, developed which motivate employees from top to bottom when pursuing growth oriented, innovation focused competitive strategies, which would require the competence of manager to execute this.

Kor (2003) developed and tested a model of multilevel experience-based top management team competence and its effects on a firm's capacity of entrepreneurial growth. The model incorporated the individual and additive effects of firm, team, and industry levels of managerial experience and the conflict effects of combining multiple levels of experience. The results indicated that founders' participation in the top management teams, and managers' experience, in the industry contributed, to the competence of the team in seizing new growth opportunities. Kor (2003) further showed that, because of conflict effects, the positive effect of founders' participation in the management team on the rate of growth weakened as either the shared teamspecific experience or industry-specific managerial experience in the team increases.

Finkelstein (1992) carried out a study in order to present a set of dimensions for measuring top managers' power and to suggest a measurement methodology to facilitate an empirical inquiry with primary propositions that managerial power was a central element in strategic choice. They found that, the ability of top managers to affect firm strategy depended largely on whether they had the requisite power to be influential. The importance of top managers' power to organizations suggests that it may be interesting to examine the distribution of power in teams. In some teams, power may reside in one or two key individuals; other teams may exhibit a more dispersed power distribution. 
The IMF management competencies framework as a starting point for developing managerial expectations helps in boosting management skills and acting as a standard measure for not only analyzing but also development of skills that contribute to the overall competencies necessary for managers' effectiveness.

\section{Summary Discussion}

Discussions on change management factors above covered: change management, development of appropriate strategies for change management, successful change management, resistance to change, approaches to revolutionary change, and effective management of radical change, change related to process improvement programs and the pace of change all of which affect both the internal and external environment of an organization. Francis and Desai (2005) postulated that contextual factors such as urgency, severity of organizational decline, productivity, and retrenchment determined the ability of an organization to turnaround but the overall factors under the control of managers contributed more, to successful turnarounds than situational characteristics. In order to manage radical change, effectively one needs to incorporate both effective communication and leadership (Smith, 2003). Whatever the type of change in any organization, it affects the people, structure, procedures or the organization's technologies (Gilley, Gilley \& McMillan, 2009). The change management factors discussed affects the external environment that in turn, impacts on the organizational mission and strategy were indicating that, change management impacts both negatively and positives on turnaround strategy.

Discussions on management competence above covered: issues related to experience of top managers, types of competencies, competencies in relation to organizational performance, management's ability to affect strategy, characteristics of competencies for either competitive advantage or advancement to senior positions in organizations, and competencies necessary to retain a CEO during turnaround. The most commonly reallocated resource in the implementation of business turnaround strategy is management (John \& Richards, 1987). The ability or "competence" of top managers to affect a firm's strategy depends largely on whether they have the requisite power to be influential (Finkelstein, 1992). The final stage to handle, when changing a CEO particularly in a declining organization, is that of considering the competencies of the incoming CEO (Castrogiovanni et al., 1992). Management competencies in an organization will influence both positively and negatively in relation to implementation of its turnaround strategy.

\section{Conclusion}

Change management in an organization originate from individual member's behaviour while organizational issues depend upon its size, culture, and levels of bureaucracy within it. Therefore, to effectively manage change, leaders need to establish the methods or approach; how to develop new culture; how to establish effective channels of communication; and how to incorporate support while offering positive leadership. Other behaviours supportive of both individuals and organization in order to realize revolutionary change include enhanced communication of change, improved financial strategies for change, and actions in support of business expansion.

Management competence in an organization include skills and past experience of its manages among other capabilities. It is, noted that managers are responsible for implementing organizational strategy and the ability of top managers to affect firm strategy depends largely on whether they have the requisite power to be influential. The importance of top managers' power to organizations is dependent upon the distribution of power within teams, which may reside in one or two key individuals. Other factors contributory to competence is founder's participation in Top management teams and managers past experience.

There is a relationship between both the change management and management competence of an organization and that of its turnaround strategy implementation.

\section{Recommendations}

It is suggested that for effective implementation of organizational turnaround strategy factors summarized in the conclusion above under change management and management competence be given more priority.

It is recommended that empirical studies be carried out to establish the following:

1. The effect of change management on organizational turnaround strategy.

2. The effect of management competence on organizational turnaround strategy.

3. The turnaround strategy critical success factors. 


\section{References}

[1] ACAS. (2009). Front line managers. Retrieved 12 18, 2013, from acas: http://www.acas.org.uk/CHttpHandler.ashx?id=308\&p=0

[2] Ahn, B. S., Cho, S. S., \& Kim, C. Y. (2000). The integrated methodology of rough set theory and artificial network for business failure prediction. Expert Systems with Applications, 18.

[3] Aladwani, A. M. (2001). Change management strategies for successful ERP implementation. Business Process Management Journal, 7 .

[4] Aosa, E. (1998). The leadership challenges facing Kenya organizations. Journal of the Institute Certified Public Account of Kenya, 23.

[5] Bibeault, D. B. (1982). Corporate Business Turnaround: How managers turn losers into winners. McGraw_Hill.

[6] Bruton, G. D., Ahlstrom, D., \& Wan, J. C. (2001). Turnaround success of large and midsize Chinese owned firms: Evidence from Hong Kong and Thailand. Journal of World Business , 36(2), 146-165.

[7] Burbank, R. K. (2005). The classic five-step turnaround process: Case study of Prodigene Inc. The Journal of Private Equity(Special Turnaround issue), 53-58.

[8] Burke, W. W., \& Litwin, G. H. (1992). A causal model of organizational performance and change. Journal of management, 18.

[9] By, R. T. (2005). Organisational Change Management: A critical Review. Journal of Change Management, 5.

[10] Castrogiovanni, G. J., Baliga, B. R., \& Kidwell Jr., R. E. (1992). Curing sick business: Changing CEOS in turnaround efforts. A cademy of Management Executive, 6(3).

[11] Chowdhury, S. D., \& R., L. J. (1996). Business Turnaround in Small Firms: An assessment of efficiency strategies. Journal of Business Research, 36.

[12] Crittenden, V. L., \& Crittenden, W. F. (2008). Building a capable organization: The eight levers of strategy implementation. Business Horizons, 51, 301-309.

[13] Crowe, T. J., Fong, P. M., \& Zayas-Castro, J. L. (2002). Quantitative risk level estimation of business process reengineering efforts. Business Process Management Journal, 8.

[14] Dulewicz, V., \& Herbert, P. (1999). Predicting advancement to senior management from competencies and personality data: A seven-year Follow-Up study. British Journal of Management, 10, 13-22.

[15] Finkelstein, S. (1992). Power in top management teams: dimensions, measurement, and validation. Academy of management journal, 35.

[16] Francis, J. D., \& Desai, A. B. (2005). Situational and organizational determinants of turnarounds. Management Decision , 43(9), 1203-1224.

[17] George, J. M., \& Jones, G. R. (2008). Understanding and managing organizational behavior. Upper Saddle River: Pearson.

[18] Gerald, C. A. (2004). Management theory and practice (6th ed.). London.

[19] Gieves, J. (2000). Introductions: the origins of organizational development. Journal of Management Development, $19(5), 345-447$.

[20] Gilley, A., Gilley, J. W., \& McMillan, H. S. (2009). Organizational Change: Motivation, communication, and leadership effectiveness. Perf. Improvement Qrtly, 21.

[21] Hambric, D., \& Schecter, S. (1983). Business Turnaround Strategies for Mature Industrial-product Business Units. Academy of Management Journal, 26.

[22] Harold, K. (1984). Instruction manual for management (8th ed.). New York: McGraw-Hill Book Company.

[23] Haron, N. H., Rahman, I. K., \& Smith, M. (2013). Management accounting practices and the turnaround process. Asian Review of Accounting, 21(2), 100-112.

[24] Hill, C., \& Jones, G. (2001). Strategic management theory (5th ed.). Hougton Mifflin Company.

[25] Hofer, C. W. (1980). Business turnaround strategies. Jounal of Busines Strategy, 1.

[26] John, A. P., \& Richard, B. R. (1987). Corporate Strategies: Aselection of Readings from Business Week (Inter ed.). New York: McGraw Hill.

[27] Johnson, L. (2004, December). Execute your strategy - without killing it. Harvard Management Update, pp. 3-5.

[28] Kavanagh, M. H., \& Ashkanasy, N. M. (2006). The impact of leadership and change management strategy on organizational culture and individual acceptance of change during a merger. British Journal of management, 17.

[29] King, A. W., Fowler, S. W., \& Zeithaml, C. P. (2001). Managing organizational competencies for competitive advantage: The middle-management edge. Academy of Management Executive, 1(2), 95-106.

[30] Kor, Y. Y. (2003). Experience-Based top management team competence and sustained growth. Organization Science, 14.

[31] Lohrke, F., Bedeian, A. C., \& Palmer, T. (2004). The role of top management teams in formulating and implementing business turnaround strategies: A review and research agenda. International Journal of Management Reviews, 5.

[32] Lorenzi, N. M., \& Riley, R. T. (2003). Organizational issues =/ change. International Journal of Medical Informatics, 69.

[33] Machuki, V. N. (2005). Challenges to Strategy Implementation at CMC Motors Ltd. Unpublished Master's thesis, Nairobi University.

[34] Maheshwari, S. K. (2000, October-December). Organizational decline and turnaround management: A contigency framework. Vikalpa, 25(4)

[35] Maheshwari, S. K., \& Ahlstrom, D. (2003). Turning around a state owned enterprise: The case of scooters in India Limited. Asia Pacific Journal of Management Conference on Corporate Turnaround, (pp. 75-101).

[36] Moran, J. W., \& Brightman, B. K. (2001). Leading organizational change. Career Development International, 6.

[37] Pandit, N. (2000). Some recommendations for improved research on corporate business turnaround. Academy of Management Review, 3 .

[38] Panicker, S., \& Manimala, M. J. (2011). Successful business turnaround: The role of appropriate entrepreneural strategies. 10th, International Entrepreneurship Forum, (pp. 1-22). Tamkeen, Bahrain.

[39] Pearce, J. A., \& Robinson, R. B. (2007). Strategic Management: Formulation, Implementation and Control. Irwin: McGraw Hill International.

[40] Porter, M. (1980). Competitive Strategy. Free Press.

[41] Pretorius, M. (2009). Defining business decline, failure and turnaround: A content analysis. SAJESBM NS, 2(1), 1-16.

[42] Rosario, R. H., Kawamura, T., \& Peiris, T. L. (2004). The Coir Fiber Industry in Sri Lanka: Reasons for its decline and possible business turnaround strategies. Agribusiness, 20.

[43] Scherrer, P. S. (2003). Management business turnaround: diagnosing business ailments. Corporate Governance, 3.

[44] Simon, S. (2012). Factors that affect the outcome of process improvement programmes in South African firms. Research report for a degree of master of science in the University of Witwatersrand, Johannesburg.

[45] Sitati, A., \& Bym Odipo, M. K. (2011). Evaluation of applicability of Altman'srevised model in prediction of financial stress .

[46] Slater, R. (1999). Saving Big Blue: Leadership lessons and business turnaround tactics of IBM's Lou Gerstner. McGraw-Hill. 
[47] Slatter, S., Lovett, D., \& Barlow, L. (2006). Leading corporate business turnaround: How leaders fix troubled companies.

[48] Smith, M. (2003). Business process design:Correlates of success and failure. The Quality Management Journal, 10(2), 38-49.

[49] Snow, C. C., \& Hrebiniak, L. G. (1980). Strategy, distinctive competence and organizational performance. Administrative Science Quarterly, 25(2).

[50] Sutevski, D. (2012). Resistance to organizational change. Retrieved November 22, 2012, from http://www.entrepreneurshipinabox.com/223/factors-that-causes-resistance-to-organizational-change/

[51] Szamosi, L. T., \& Duxbury, L. (2002). Development of a measure to assess organizational change. Journal of Organizational Change Management, 15.

[52] Thompson, A. A., \& Strickland, A. J. (1993). Strategic Management. McGraw-Hill Inc.

[53] Thompson, A. A., \& Strickland, A. J. (1999). Strategic Management: Concepts and Cases. Irwin: McGRAW-Hill.

[54] Tower, S. (1994). Business Process Reengineering: A practical handbook for executives. Stanley Thomas Ltd.

[55] Turnaroundstrategy.net. (2013, 11 13). Turnaround Strategy. Retrieved 2013, from Turnaroundstrategy.net: http://www.turnaroundstrategy.net/

[56] Tyrol, F. (2007). Exploring Organizational Identity in the Context Transformational Change. Academy of Management Review, 25.

[57] Waldersee, R., \& Griffiths, A. (2004). Implementing change: matching implementation methods and change type. The Leadership \& Organization Development Journal, 25(5), 424-434.

[58] Wheelen, T., \& Hunger, J. (2001). Strategic Management and Business Policy. Addison Wesley Reading.

[59] Whonderr-Arthur, J. (2009, April Saturday). Strategy Implementation. Retrieved 12 22, 2013, from Businessballs Community Blogs: http://community.businessballs.com/blogs/strategy-implementation.html 